\title{
A NEW NAME FOR ALSOPHIS ANTILLENSIS
}

\author{
BY CHAPMAN GRANT
}

Schlegel (1837) described Psammophis antillensis from St. Thomas, Guadeloupe, Martinique and Cuba. Brongersma (1937) revised this composite species, but left a few loose ends which this paper endeavors to catch up.

The Alsophis which inhabits most of the islands and islets east of Puerto Rico has long been known as Alsophis antillensis (Schlegel). If a sufficiently large series of specimens could be assembled from each islet of this area, an average difference, possibly of subspecific value, between many of the populations would be apparent. The large series which I have collected from some of the islands tends to bear this out (Grant, 1932). On the other hand, many specimens from most of these localities could be matched in a large series from almost any other island in his area.

Color pattern has played an important part in the taxonomy so it may be advisable to explain how Stejneger's fig. 174 came to be considered typical of the pattern of antillensis.

Stejneger habitually described a single specimen of a species in detail and then discussed variations in a separate paragraph. When he summarized Alsophis antillensis (Stejneger, 1904; p. 704 et seq.) he had material from St. Thomas, which was one of the type localities, but these specimens were not in good condition. Therefore he selected a half-grown, distinctly patterned specimen from Culebra Island, USMN No. 25557, and illustrated its color pattern at midbody with his Fig. 174 (see cut). He did not state that this pattern was typical of the species. He merely remarked that the marking on the fifth scale row appeared to be constant, but did not state how far it extended posteriorly, nor did he mention the pattern depicted on the eighth row in Fig. 174. He said: "On the whole the coloration is much as in the specimen described above. ..." The specimen "described above" was not the one figured, but No. 25554, an adult, doubtless with a dimmer pattern than that of the half-grown specimen figured.

I have found in well-preserved material from the Virgin Islands area that the pattern on the eighth row is usually wanting and the pattern on the fifth may not extend beyond the region of the neck. Anteriorly the pattern on the fifth row may be duplicated on the sixth row and an inverted pattern may be found for a short distance on the fourth row. Note that the fourth row is dropped at about the 108th ventral, or posterior to the middle of the body. If the pattern extends beyond this point it appears to occupy the fourth row, but it is in reality on the same row on which it originated 
the fifth. In my observation a one row pattern does not switch from one row to another.

Stejneger (p. 704) pointed out that the type localities of Alsophis antillensis, having been designated St. Thomas, Guadeloupe, Martinique and Cuba, obviously constituted a composite species. Schmidt (p. 140) agreed, but added that "the name has come to be restricted to the Virgin Islands form by the consensus of opinion among herpetologists." The specimen that Schmidt summarizes is not from the Virgin Islands despite his restrictions, but was taken on Culebra. He even records the species from Puerto Rico (pp. 139, 141). He states (p. 139) that Günther (1859; p. 210) restricted the species to St. Thomas, but Brongersma (p. 3) denies this.

Schmidt requested Brongersma, who had access to the type material, to make an examination and publish his findings, which he did. The results of Brongersma's paper may be thus summarized.

\section{SUMMARY OF BRONGERSMA'S PAPER}

1. Psammophis antillensis Schlegel, is a composite species which the describer thought had wide distribution.

2. A lectotype must be selected to restrict the name antillensis to one of the components.

3. The lectotype must be selected from among the specimens upon which the description was actually based and not on others which Schlegel merely examined.

4. Schlegel mentions three cotypes of which the measurements are the only clues to their identity. These specimens are in the Leiden Museum:

a) No. 767 Leiden, labeled Psammophis antillensis, from Martinique, is in reality Eudryas boddaertii (Sentzen), from Venezuela.

b) No. 768 Leiden, labeled Psammophis antillensis, from Guadeloupe, chosen by Brongersma as the lectotype, is identical with Alsophis leucomales leucomales (Dum., Bibr. \& Dum.), from Guadeloupe.

c) No. 769 Leiden, labeled Psammophis antillensis, from St. Thomas, collected by Richard, is in reality Alsophis sancticrucis (Cope), from St. Croix.

5. Schlegel did not use St. Thomas specimens in describing Psammophis antillensis.

6. As a result of Brongersma's action the Guadeloupe form becomes Alsophis antillensis (Schlegel) and leucomales becomes a synonym.

7. The St. Thomas form is unnamed unless, as Schmidt says, (pp. 139, 141 ) it is identical with Alsophis anegadae Barbour, in which case it takes that name. 


\section{DISCUSSION}

I will endeavor to show that:

1. Leiden No. 769, labeled St. Thomas, collected by Richard, is not $A$. sancticrucis. That neither Brongersma nor Schmidt proved that it came from elsewhere than St. Thomas as labeled.

2. Schmidt did not prove A. anegadae identical to the St. Thomas area populations and I endeavor to show that it is different.

3. A. nicholsi Grant from Buck (or Capella) Islands is subspecifically different from the St. Thomas area populations and becomes A. nicholsi nicholsi Grant.

4. St. Thomas etc. have a population differing subspecifically from $A$. nicholsi and is therefore given a new subspecific designation.

Brongersma (p. 3) eliminated Leiden No. 769, labeled Psammophis antillensis, from St. Thomas, as a possible lectotype on the following grounds; "The coloration of the anterior part of the body is not that which Stejneger (p. 705, fig. 174) and Schmidt (p. 142, fig. 47) describe as typical for Alsophis antillensis from St. Thomas." Note that Brongersma infers that the descriptions and figure referred to are of a St. Thomas specimen. Reference to Stejneger shows that his fig. 174 is of USNM No. 25557 which was taken on Culebra Island and not on St. Thomas. Stejneger's description (pp. 704-705) is of USNM No. 25554 also from Culebra. Schmidt's fig. 41 is a copy of Stejneger's fig. 174. Schmidt (p. 141) says: "Much the best description extant is that of Stejneger, based on a Culebra specimen. ..." Apparently the only color pattern of which Brongersma was aware was that of Culebra specimens.

Probably Brongersma would have avoided a change from a long established name by selecting Richard's St. Thomas specimen for the lectotype had he known all the facts. As it was he sent a "rough sketch" (p. 3) (see cut) of Richard's St. Thomas cotype, 769 Leiden, to Schmidt who identified the sketch as Alsophis sancticrucis (Cope) although Schmidt had neither St. Thomas nor St. Croix specimens for comparison. However, the sketch showed what appeared to be crossbands and Brongersma (p. 3) says the specimen has more or less distinct crossbands. On p. 4 he states that there is a specimen in the Paris Museum, No. 3574, also labeled "St. Thomas, Richard," I believe that since this specimen is unchallenged as a St. Thomas specimen, Richard's labels have not been proven untrustworthy.

I thought it necessary to locate a specimen of sancticrucis so that the above mentioned sketch might be compared to a real specimen. Mrs. Gaige of the MZUM, Mr. Loveridge of the MCZ, Mr. Bogert of the AMNH and Miss Margaret Storey of Stanford University all kindly answered my query to the effect that they had no specimen of sancticrucis. Dr. Cochran obligingly stated that the USNM had a specimen catalogued as sancticrucis 
USNM No. 11105 from Guadeloupe, but the locality makes this specimen without interest in this case. Dr. E. R. Dunn kindly reported that the ANS had the type, No. 5404 from St. Croix. I therefore forwarded him the sketch for comparison. He stated in a letter dated Feb. 1, 1945:

"I checked the sketch of Leyden 769 directly with ANS 5404, which is one of Cope's original specimens of sancticrucis. The markings of the two differ considerably. The type has a light line along the meeting edges of scale rows two and three; this does not appear in the sketch. The type shows light bars running directly across the back; the sketch shows some vague and oblique light marks which do not cross the back. The ANS has two specimens from the 'West Indies' which agree closely with the type, but are more vividly marked. In my opinion the Leyden sketch does not represent a specimen of sancticrucis."

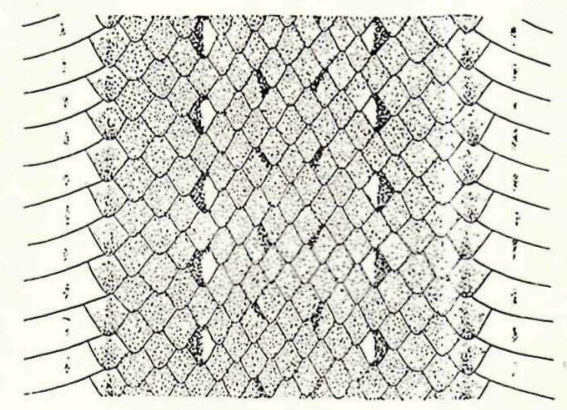

Fig. 174.-ALsophis antillensis. Color pattern around middle of body. No. 25557 , L.S.X.M.

FIG. 5

The reader may compare the sketch, fig. 5 with the photo of the type, fig. 6, for himself. I invite attention to the "pattern" on the sketch. A preserved specimen of this genus is prone to lose scales by handling. When a scale rubs off it leaves a light colored area caused by exposing the lighter colored skin. The sketch shows what might well be a specimen that had received considerable handling.

I believe that the above evidence, with the illustrations, is sufficient to prove that Leyden 769 labeled St. Thomas is not sancticrucis and that there appears to be no reason to doubt that it came from St. Thomas.

There is little doubt but that Brongersma would have given the St. Thomas population a name had not Schmidt (p. 139) synonymized antillensis and anegadae, although he had neither St. Thomas nor Anegada material at his disposal. Schmidt stated in a letter to me dated Jan. 11, 1943: "As for the problem of anegadae, my reference of it to antillensis was based on very general resemblances." Schmidt (p. 139) includes anegadae in the synonomy of antillensis. He explains his action thus (p. 141): "The 
two specimens (of antillensis from Puerto Rico) agree closely in coloration with the color variety described by Barbour from Anegada and, as 1 do not wish to admit of a discontinuous distribution of anegadae, it seems best to include both Puerto Rican and Anegadian specimens with antillensis."

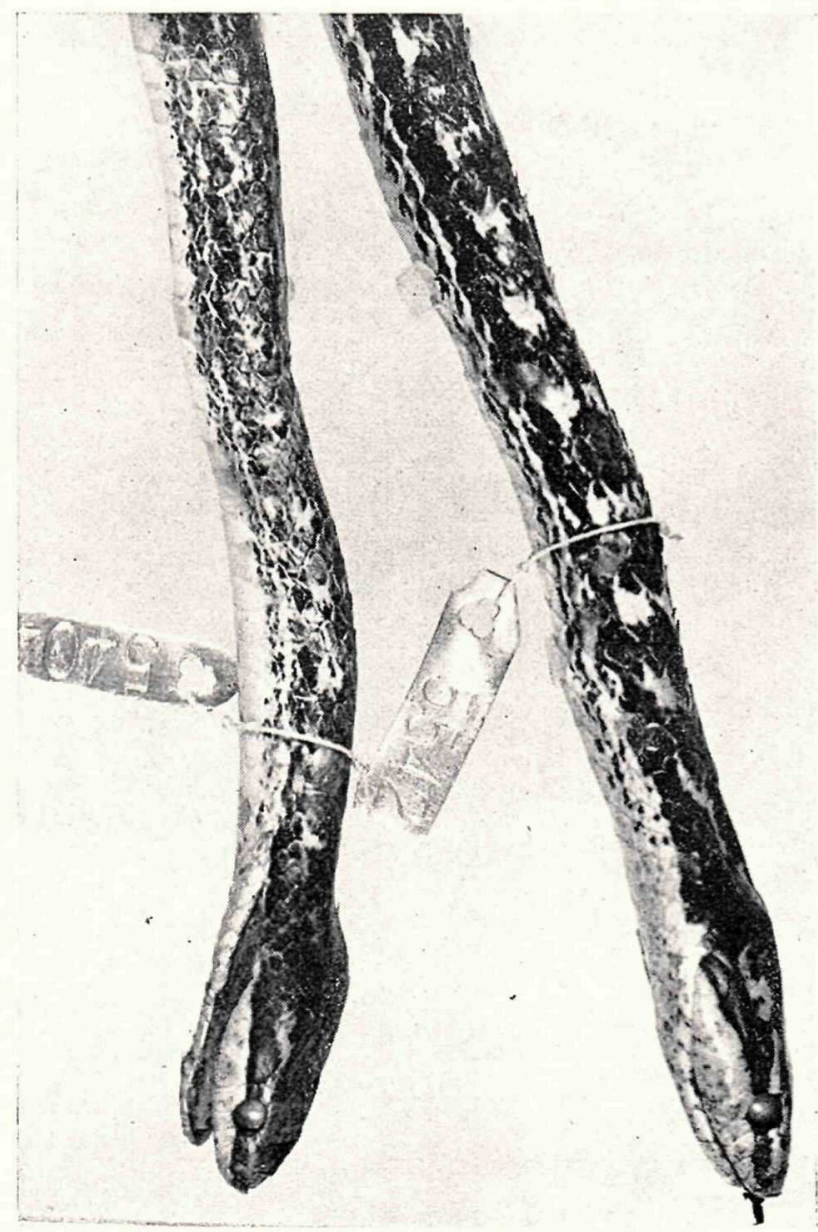

FIG. 6

Brongersma stated (p. 5): "If Schmidt (pp. 139, 141) is right in referring Alsophis anegadae to the synonymy of the species occurring in St. Thomas, this name must replace Alsophis antillensis auct. (non Schlegel). As I did not examine . . . anegadae ... I cannot form an opinion on the possible identity ... and ... must leave it to future authors. . . "'

Barbour (p. 102) in his original description of anegadae says: "Two 
snakes from Anegada are both alike in having a squamation similar to antillensis but (differ from antillensis) in being pale ashy gray in color, the fifth scale row not parti-colored, but with a median streak of black. The upper lips are immaculate white, unspotted."

I took two specimens on Anegada, both were light tan, not gray, although I have taken gray specimens of this genus on some other islands, Peter Island for example. Both Anegada specimens had the usual particolored fifth row scales, differing from Barbour's description of anegadae. One, MZUM No. 80639A, has lips almost immaculate; No. 80639B has spotted lips. Both have numerous dark spots on all dorsal rows, a feature occasionally found on specimens from the other islets and are somewhat similar to variegatus. I would suggest the following diagnosis for anegadae: "A small, pale form differing from the populations on nearby islands in having scale pores much reduced in numbers and having dark flecks on the dorsal scales above the fifth row."

Dr. Cochran kindly sent me 9 specimens of "A. antillensis" labeled from St. Thomas and one specimen from Water Island. These specimens divide into three groups as far as pattern is concerned. USNM Nos. 98966, A12403 and 66523 have a dark, broken line (almost continuous on 98966) on the fifth row for the entire length of the body and in addition all rows below the patterned row are dark; rows 7-8 have spots near neck. (Note. Frequently the markings occur between rows or rather occupy the lower part of one row and the upper part of the adjacent row. I designate the rows by number to express this type of marking.) This group presents a pattern different from any I have seen. If it were possible to correlate them with an area, they would represent a well differentiated population. Nos. 66524, 12403 and 75866 have the pattern for half the length of the body and a few spots on 7 near neck; in Nos. 66525 and 66522 the pattern is reduced to about one fourth the length of body. This group agrees pretty well with the "typical antillensis pattern". No. 13857 is a snake of the general appearance of the nicholsi pattern, described below, with 4-5 marked half the length of the body and 7-8 marked on the neck. These marks are faint and the general appearance of the snake is like nicholsi. No. 52547 labeled from Water Island has the appearance of a reduced "antillensis pattern" with 5-6 spotted a fourth the length of body and 7-8 marked on neck.

Assuming that all labels are correct it would appear that the St. Thomas population had a greater diversity of patterns than that of any other island in this area and that the Buck or Capella Islands pattern was approached on St. Thomas on USNM No. 13857, reducing the nicholsi population to subspecific rank. No "antillensis pattern" has yet been taken on Buck or Capella Islands. 
My original diagnosis of nicholsi states: "A pale form with the squamation of antillensis but the pattern of portoricensis, namely differing from typical antillensis in that the lateral stripe on scale rows four and five is visible only on the neck, where it is very faintly indicated, the broad dark dorsal band is likewise faint and is evidenced only by a gradual darkening of the more dorsal scales and the pattern on the eighth row is missing." Under the description of the type I said: "In life the dorsal ground color is pale olive green, which fades to pale brown in alcohol. This color is light laterally, but becomes more intense dorsally. Each scale with a diffused darker margin. On the neck there is evidence of the characteristic dark lateral band on scale rows four and five, but the characteristic marks which occur on the eighth row of antillensis are missing." This quotation shows that I was under the influence of fig. 174. The type locality of Alsophis nicholsi is Buck or Capella Islands just off St. Thomas. The specimens I took on Water Island approached nicholsi in general appearance.

The type of Alsophys nicholsi is MZUM No. 80648; paratypes 80640, 80641 and MCZ No. 46503. This form should henceforth be called Alsophys nicholsi nicholsi Grant. The type locality and range is Buck or Capella Islands ${ }^{1}$ off St. Thomas, Virgin Islands.

The population occurring on St. Thomas and the Virgin Islands, excepting Anegada and St. Croix and the islands and islets east of Puerto Rico, excepting Vieques which is said to have had portoricensis, should henceforth be known as: Alsophis nicholsi richardi new subspecies.

\section{Alsophis nicholsi richardi², new subspecies}

Type:-USNM 66522; E. Sebastian collector; St. Thomas, V.I.; 1923, male.

Paratypes:-USNM 12403A, 12403B, A. H. Riise collector; St. Thomas, V. I.

Diagnosis:-A 19 scale row Alsophis bearing a broken row of particolored

${ }^{1}$ There are several islets called "Buck Island" among the Virgin Islands. Buck, meaning goat, is probably an influence left by the Dutch inhabitants of the Islands. It was customary to release goats on islets and capture or shoot the increase for food. Off St. Thomas lie two tiny islets nestling together like two commas with their tails separated by only about 20 feet of shallow water. Passing by these islands one would ordinarily think of them as a single island. On the charts these specks are named Capella because they are twin islets-Capella being the name of a twin star in the heavens. The fact that "Capella" means small or young goat is purely coincidental to the local name of Buck. Therefore the proper names of these rocks are Buck Island or Capella Islands.

${ }^{2}$ Named in honor of the original collector. It is regrettable that the two genitives should occur in the name, but I prefer to honor Richard rather than to adhere to euphony. 
scales on the 5th row from the neck to a varying distance along the body; usually particolored scales above fifth row particularly at nape, occasionally extending some distance posteriorly on the eighth row. Closest to $A$. anegadae, which is a smaller, pale form with scale pores reduced in numbers and having frequently a preponderance of single pores and dark flecks on scales above the fifth row; differs from $A$. nicholsi nicholsi, which has no lateral pattern or a greatly reduced one, and from $A$. portoricensis, which bears a reticulated pattern.

\section{SUMMARY}

Brongersma studied three cotypes of Psammophis antillensis Schlegel, which represented three species. From these he desired to select a lectotype in order to restrict Asaophis antillensis (Schlegel) to a single species.

Acting on his right to select any of the three, he selected a Guadeloupe specimen to be the lectotype of Alsophis antillensis (Schlegel).

His action left the Virgin Islands area population, which had long been known as $A$. antillensis, without a name, unless as Schmidt claimed, $A$. anegadae Barbour and the Virgin Islands area population were identical. If this were so, the entire population would become $A$. anegadae.

The identity of the Anegada and Virgin Islands area populations has not been proven and there is good reason to believe them distinct.

Alsophis nicholsi Grant, with Buck or Capella Islands as the type locality becomes Alsophis nicholsi nicholsi Grant, with intergrades on Water Island.

The population on the remaining Virgin Islands, excepting Anegada and St. Croix, and on the islands and islets east of Puerto Rico, excepting Vieques, becomes Alsophis nicholsi richardi Grant.

\section{LITERATURE CITED}

Barbour, Thomas. 1917 Notes on the herpetology of the Virgin Islands. Proc. Biol. Soc. Wash., 30: 97-104.

Brongersma, L. D. 1937 The types of Psammophis antillensis Schlegel. Zool. Mede., 20: 1-5.

Grant, Chapman. 1932 The genus Alsophis in the Puerto Rico area. Jour. Dept. Agri., Puerto Rico., 16: 149-151.

1937 Herpetological notes with new species from the American and British Virgin Islands, 1936. Idem., 21: 503-522.

GÜNTHer, A. 1859 On the reptiles from St. Croix, West Indies, collected by Messrs A. and E. Newton. Ann. Mag. Nat. Hist., 4: 209-217.

Schlegel, H. 1837 Essai sur la physionomie des serpens. Leiden., 1: 28, 251; 2: 606,6 .

Schmidt, K. P. 1928 Amphibians and land reptiles of Porto Rico, with a list of those reported from the Virgin Islands. N.Y. Acad. Sci., 10: 1-160.

Stejneger, Leonhard. 1904 The herpetology of Porto Rico. U.S.N.M. No. 129., 549-724. 